International Journal of Engineering \&Technology, $7(1.7)(2018) 38-42$
International Journal of Engineering \& Technology
SPC
Website www.sciencepubco.com/index.php/IJET
Research paper

\title{
Comparative study on satellite-based data communication techniques
}

\author{
T. Sujithra ${ }^{1}{ }^{*}$, G. Nivedhitha ${ }^{1}$, S. Durai ${ }^{1}$, A. Suresh ${ }^{2}$ \\ ${ }^{1}$ Assistant Professor, Department of Computer Science and Engineering, School of Computing, Vel Tech Rangarajan \\ Dr. Sagunthala R\&D Institute of Science and Technology, Avadi, Chennai-62, TamilNadu, India \\ ${ }^{2}$ Professor \& Head, Department of Computer Science and Engineering, Nehru Institute of Engineering and Technology, \\ T. M. Palayam, Coimbatore-641105, TamilNadu, India \\ *Corresponding author E-mail: sujithrat@veltechuniv.edu.in
}

\begin{abstract}
Satellite communication is highly useful in collecting data from human unattended area, early warning of natural disasters, earth observation and so on. Numerous work has been carried out in the area of satellite based communication and networking. It is an inseparable component from the Global Network infrastructure. In this study, we recapitulate, compare and comments on proposed approaches for the satellite based communication with keeping in view the parameters such as efficient data transfer between the satellite and the ground station, various on-board data processing techniques, prioritizing the payload data, load balancing and optimizing energy consumption issues.
\end{abstract}

Keywords: Satellite; on-Board Data Processing; Data Download Plans; Ground Station; Load Balancing; Payload.

\section{Basic elements of satellite communi-cation}

The technology improvement and the need of multimedia services (e.g E-mail, Internet, weather report analysis, television, Video on Demand) forces a redefinition of the correspondence with satellite communication system. In common, Satellite communication is used when two stations on the earth cannot communicate by using radio broadcast with each other because of longer distance, in which satellite acts as relay between these two stations. One Earth Station transmits its signal to the satellite by means of Uplink frequency. At that point, the satellite transponder changes over the signal and sends it down to the second earth station through down- link frequency. Satellites must be situated in orbits with various sizes and different in shapes (roundabout / curved). In view of the orbital range, all satellites can be categorized as one of the accompanying three classifications;

1) LEO: Low Earth Orbit.

2) MEO: Medium Earth Orbit.

3) GEO: Geostationary Earth Orbit.

4) HEO: Highly Elliptical Orbit. Furthermore, Tale 1.1 shows the operational considerations of satellite orbits in detailed manner.

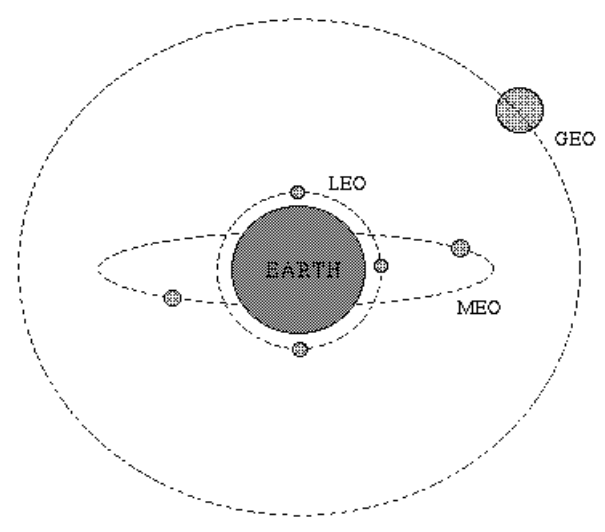

Fig. 1: Classification of Orbital. 
Table 1.1: Satellite Orbits Operational Considerations

\begin{tabular}{|c|c|c|c|c|}
\hline & Geostationary Orbit & Low Earth Orbit & Medium Earth Orbit & Highly Elliptical Orbit \\
\hline Altitude & $35-786 \mathrm{~km}$ & $750-2000 \mathrm{~km}$ & $10000-20000 \mathrm{~km}$ & $\begin{array}{l}\text { Apogee: } 40000-50000 \mathrm{~km} \\
\text { Perigee: } 10000-20000 \mathrm{~km}\end{array}$ \\
\hline Coverage & $\begin{array}{l}\text { Continuous coverage using } \\
\text { single satellite, global coverage } \\
\text { using a minimum of three satel- } \\
\text { lites }\end{array}$ & $\begin{array}{l}30 \text { satellites are re- } \\
\text { quired to cover global, }\end{array}$ & $\begin{array}{l}10 \text { and } 20 \text { satellites are } \\
\text { required to cover globally }\end{array}$ & $\begin{array}{l}3 \text { or } 4 \text { satellites are required } \\
\text { to coverage to a region }\end{array}$ \\
\hline Visibility & $\begin{array}{l}\text { Poor visibility in built-up and } \\
\text { urban region }\end{array}$ & $\begin{array}{l}\text { More than one satellite } \\
\text { is visible at any given } \\
\text { time }\end{array}$ & $\begin{array}{l}\text { Good to excellent global } \\
\text { visibility }\end{array}$ & $\begin{array}{l}\text { High guaranteed elevation } \\
\text { angle to satellite for north- } \\
\text { ern and southern tempera- } \\
\text { ture latitudes. }\end{array}$ \\
\hline Network complexity & $\begin{array}{l}\text { Straight forward network archi- } \\
\text { tecture, no handover between } \\
\text { satellites during call. }\end{array}$ & $\begin{array}{l}\text { Handover between } \\
\text { satellites required dur- } \\
\text { ing a call, large number } \\
\text { of gateways may re- } \\
\text { quired. }\end{array}$ & $\begin{array}{l}\text { Handover between satellites } \\
\text { required but not frequently } \\
\text { as LEO. }\end{array}$ & $\begin{array}{l}\text { Handover between satellites } \\
\text { occurred three to four times } \\
\text { occurred daily. }\end{array}$ \\
\hline Technology & $\begin{array}{l}\text { Used to provide mobile ser- } \\
\text { vices, }\end{array}$ & $\begin{array}{l}\text { Mixed response with } \\
\text { respect to quality of } \\
\text { service. }\end{array}$ & $\begin{array}{l}\text { Commercial mobile satellite } \\
\text { services }\end{array}$ & $\begin{array}{l}\text { Has been used to provide } \\
\text { TV services }\end{array}$ \\
\hline
\end{tabular}

\subsection{Satellite communication channels}

It is categorized based on

- Broadsurface coverage of the earth's exterior.

- Extendedcommunication delays.

- Televise transmission.

- Huge Channel Bandwidth.

- Distance Independent Communication costs.

\subsection{Frequency bands}

Satellite connections will add divergent frequency teams and utilize distinctive transporter frequencies for the up-interface and down-interface. Every style of satellites use separate waveband that has to diverge from others. Table 1.2 demonstrates the foremost well-known frequency teams. the employment of $\mathrm{C}$ bunches was most common in period of play satellite frameworks. but this band is presently swarmed as terrestrial microwave associates in like manner use these frequencies. this example is towards the upper frequencies of unnilquadium and Hindu deity gatherings. Enfeebling see able of rain is an essential issue in each of those gatherings. Furthermore because of the upper frequencies, microwave instrumentality remains to an excellent degree expensive, particularly within the Hindu deity band [2].

Table 1.2: Frequency Band Allotment for Some Ordinary Bands

\begin{tabular}{|c|c|c|c|}
\hline $\begin{array}{l}\text { Frequency } \\
\text { Band }\end{array}$ & $\begin{array}{l}\text { Up- } \\
\text { Interface } \\
\text { (GHZ) }\end{array}$ & $\begin{array}{l}\text { Down-Down Inter- } \\
\text { face(GHZ) }\end{array}$ & Problem Factors \\
\hline $\mathrm{C}$ & $4(3.7-4.2)$ & $6(5.925-6.425)$ & $\begin{array}{l}\text { Interfering With } \\
\text { Ground Links }\end{array}$ \\
\hline $\mathrm{Ku}$ & $\begin{array}{l}11(11.7- \\
12.2)\end{array}$ & $14(14.0-14.5)$ & $\begin{array}{l}\text { Reduction Due To } \\
\text { Rain }\end{array}$ \\
\hline $\mathrm{Ka}$ & $\begin{array}{l}20(17.7- \\
21.7)\end{array}$ & $30(27.5-30.5)$ & High Kit Cost \\
\hline $\mathrm{L} / \mathrm{S}$ & $\begin{array}{l}1.6(1.610- \\
1.625)\end{array}$ & $2.4(2.483-2.500)$ & $\begin{array}{l}\text { Interference By } \\
\text { Means Of Ism Band }\end{array}$ \\
\hline
\end{tabular}

Display day Satellites ar oft outfitted with varied transponders. The realm of the world's surface secured by a satellite's transmission pillar is insinuated because the "impression" of the satellite transponders. The up-interface is a very directional, purpose to purpose associate employing a high get dish receiving wire at the bottom station [2]. The down association will have a broad impression giving extension to a liberal scene or a "spot shaft" are often accustomed focus high power on somewhat space thus requiring cheaper and a lot of diminutive ground stations. additionally, some satellites will powerfully divert their bars and later modification their scope region.

\subsection{Application interface standards}

For digitized content, quality is set at the source encoder and transmission just presents time delay. For a satellite bounce, this deferral is little contrasted with that of pressure/decompression. The earthbound interface worried about DVB and computerized TV by and large is called ASI, a rapid serial association utilized basically on the uplink side. Telephone utility is normally conveyed on a simple premise (2-wire or 4-wire). An appropriately built satellite voice circuit meets the as of now acknowledged standard of $400 \mathrm{~ms}$ add up to delay, including the additional postponement for discourse handling (e.g., pressure and decompression, if connected), steering and exchanging. Significantly, such a satellite circuit will sound preferred to supporters over easygoing voice over IP associations through the Internet [3].

\section{Effective data transfer between satellite and ground station}

Compelling and effective satellite interchanges relies upon the kind of regulation and different access utilized by transmitting client terminals and earth stations. Reflecting the exchange of the digital mobile (cellular) measures, satellite various access strategies run the array of time division, frequency division and code division code division multiple approaches.

\subsection{Conventional system}

Transmitter data rates for low-Earth-Orbiting (LEO) carry have genuinely been reasonably low (customarily between two or three kilobits/s and two or three megabits/s). Associations for LEO carry transmitters are immediate to execute and can consistently be capable at S-band with a 3-watt transmitter and a low-pick up recieving wire [5]. For higher data rates, nevertheless, more practical isotropic emanated control (EIRP), which can be recognized by growing the transmitter control and using a high-get accepting wire, is required.Expanding the transmitter control is bothersome due to the related increments in DC power, weight, and cost, though enhancing the reception apparatus pick up is a superior arrangement if the radio frequency (RF) is sufficiently high to keep up a little gap estimate. Some frequency groups, be that as it may, have a farthest point on the power thickness permitted at the Earth's surface to counteract impedance with earthbound microwave frameworks. This imperative places a maximum farthest point on the EIRP.

\subsection{Modulation scheme for LEO}

Low Earth Orbit (LEO) satellites are twisting up dynamically renowned for correspondences purposes [2]. Central focuses over 
geostationary satellites join that operation from a low earth circle requires less transmitter control radio wire get and comes into viewpoint of each point on earth no not as much as a couple of times every day. A further favored point of view is that change and dispatch costs are a little measure of the cost of a geostationary satellite. LEO satellites, not at all like geostationary satellites which are reliably in a settled position in the sky concerning a ground station, vary in rise and banner quality. As they drop towards the horizon, falls apart the banner and the banner is impacted by obscuring and shadowing. Settled change designs are planned to adjust to the most negative situation hail conditions that the system will work under and can't misuse the more grounded signal conditions that occur at higher ascents. An adaptable change plot that can assemble the rate of data transmission is needed. This structure should be prepared for changing its rate on account of the present banner conditions. The modification/coding design was made in light of the fact that out of Amateur Packet radio and can be consolidated on a future endeavor.

The LEO satellite channel undergoes the following degradations:

\subsubsection{Fading and shadowing}

Multipath blurring and shadowing turn out to be increasingly serious as the separation from the beginning the satellite abatements. At low heights the specular factor turns into the indistinguishable as that of the disperse flag and Rayleigh blurring happens.

\subsubsection{Doppler shifts}

The movement of the LEO satellite gives rise to Doppler shifts The Doppler frequency multiply for a LEO satellite ranges from around $2 \mathrm{kHz}$ to $50 \mathrm{kHz}$.

\subsubsection{Interleaving depth}

Interleaving is utilized to give a memory less channel. On the off chance that the interleaving profundity isn't more prominent than the greatest foreseen blur profundity corruption will come about.

\subsubsection{Adjoining channel interference}

The satellite station is a channelized domain and will experience the ill effects of corruption from contiguous stations. The satellite station was demonstrated as a Gaussian station that experiences Rician/Rayleigh blurring. Interleaving was utilized to estimate a memory less channel. To give diverse rates of transmission, it is proposed to utilize QAM tweak with various group of stars designs (eg. 18QAM, CROSS-32 and so forth.) So as to give distinctive rates of transmission, K. Butchart proposed to utilize QAM adjustment with various group of stars designs (eg. 18QAM, CROSS-32 and so on.).

Trellis coding is utilized keeping in mind the end goal to accomplish a coding pick up with these star groupings. A 8-dimensional trellis coded adjustment conspire, portrayed by LYE was picked since it enables diverse heavenly bodies to be utilized. While utilizing a similar rate 314 convolution encoder. This framework utilizing a twenty point heavenly body. The eight dimensional trellis code (4 progressive two dimensional groups of stars) additionally takes into account a littler group of stars extension proportion (eg 16-QAM was expanded to a 20 point heavenly body) Rotational in-difference to 90 degrees is additionally simple to accomplish with the WE1 framework.

\section{Onboard processing techniques}

Due to expanding information rates created by the new age of instruments (high spatial, radiometric and ghostly determination) for earth perception and science missions, satellite payloads are ending up increasingly mind boggling and this pattern actuates expanding necessities as far as installed stockpiling and preparing capacities. To confront both the information administration (ac- cessible mass memory) and the information transmission (accessible transfer speed), numerous current $R \& D$ exercises ponder how to move the information handling from the Ground Segment to the Space Segment through the improvement of alleged On-board Payload Data Processing [1]. The main objective of onboard data processing is to filter the useful information from the raw data that is acquired by the instrument. Finally, data reduction work flow is moved from the ground to the space segment. Additionally, onboard data processing includes the data acquisition, transfer, storage, data compression and transmission to ground of instrumentFurthermore,the measure of crude information created by current instruments surpasses the downlink capacity, prompting the need of actualizing a choice or a pressure component locally available [3], [4]. On a similar line, for observatory sort of science missions, on board independence can bring huge points of interest. This makes it is necessary to use various signal processing and compression techniques to reduce the amount of data. It is equally important to have high speed data links, large on-board storage capabilities and digital signal processors available that are fast enough handle data in the range of gigabytes per second [5], [6].

Classical on-board payload data systems use synchronous pipeline architecture.

Mandatory functions of Classical On-board payload data systems include:

- Gathering/multiplexing information streams delivered by sensors and instruments

- Short-termcapacity of the obtained information to overcome any issues between following ground station deceivability periods

- Formatting of the downlink information stream for ground transmission

Some of the additional responsibilities of Onboard data processing includes:

Data Filtering, when the processing essentially reduces the amount of data (e.g. by Fourier or de-correlation transforms)

- Data Compression, when the data relationship can be decreased to a lower entropy level

- Data Selection, when parameters, derived on-board, allow selecting /discarding data for ground transmission.

Philippe Armbruster, presented progressed on-board Payload Data Processing frameworks. It is advanced from simply synchronous pipelines to more adaptable models. In which, nonconcurrent SpaceWire systems is utilized for dealing with variable information rates. This component is valuable for information pressure and fundamental for lossless plans. Moreover, on-load up operations can be more proficient and adaptable as required for example by the expected NGST instruments operations that might be founded on an occasion driven working worldview, typically free of supreme time labelled directing. Besides, SpaceWire in light of load up systems can bolster "Quicker than Real Time" administrations permitting a superior treatment of plan edges which instead of being lost amid the greater part of the operational stages, can be utilized for extra items elaboration.

\section{Prioritization models and load balancing}

Load adjusting adequately allocate payloads to satellites can radically decrease the general advancement, organization, and support costs. For the most part, the payload choice issue is comprehended either by an advisory group in a specially appointed way or it is illuminated diagnostically. Payload goals depend on the mission destinations and necessities. At that point the execution limits of the targets are set up, including how the end-UIs with the payload. In view of the targets, applicant payloads are recognized and investigated by estimating candidate payload characteristics. Prioritization means arrange the items depends on the order of their relative importance [7]. And the Priority list will be prepared based on the list only the resource will be selected for the execution. In satellite the process is budget level, and the resources are items. From the list of items only we are going to create priority 
list. If the budget level having the capacity of five items then only five items will be selected from priority list, if capacity two only two items will be selected from priority list etc.. For selecting items from the list we can apply either knapsack problem or the travelling salesperson collecting gifts from different cities by visit problem.

Jung created method for parceling spending range for the backpack issue and decides the related best arrangement of things to incorporate under each segment. The system contains two stages that will be rehashed until the point when entire spending plan is divided.The first step solves the maximum budget. The second step is to comprehend utilizing the ideal incentive from the initial step. This system is successful when an unverifiable spending will be acknowledged right on time in the basic leadership process and the chosen things don't need to be reliable between different spending levels.

Morton et al. made stochastic framework boycott models that might be used to choose the best regions at which to present nuclear acknowledgment sensors. Two models were introduced, the stochastic framework boycott issue (SNIP) and the seen stochastic framework preclusion issue (PSNIP). The objective of the two models is to restrict the probability that a sprinter will successfully explore the sort out without being perceived.Container and Morton illuminated the system prohibition show, SNIP, utilizing principally the L-formed disintegration strategy. Brilliant et al. analyzed the orienteering issue, and Tang and MillerHooks and Laporte and Martello talked about a comparative issue, the particular voyaging sales representative issue.

Senior member et al. talked about the estimation of adaptively in stochastic pressing and stochastic backpack issues. Mettu and Plaxton analyzed the online middle issue, which is a variation of the k-middle issue. There are a few ranges in the cutting edge that utilization the possibility of prioritization: the orienteering issue, the particular voyaging businessperson issue and the stochastic pressing issue. In any case, these issues do exclude dubious data, e.g., the cutoff for the orienteering issue is deterministic. The answer for the online middle issue yields a need list over some questionable information, in any case, the model was created utilizing a most pessimistic scenario examination as opposed to accepting a likelihood circulation for the obscure parameter.

\section{Optimization models for payload selection}

Specifically, [8] organize satellite transport payloads to amplify the normal reward for incorporating these payloads in the heavenly body. Payloads (or abilities) are incorporated on each satellite dispatch. Accept that just a single payload of any given sort might be incorporated on a solitary dispatch. This limitation can be bypassed, if the need emerges, by incorporating the payload in the arrangement of practical payloads more than once. On each satellite, the satellite transport is obliged by its building determinations, i.e., the physical amounts that point of confinement which payloads might be incorporated into the satellite transport.

To begin with, the heaviness of the payloads which may be incorporated on the satellite must be considered on the grounds that the dispatch vehicles that lift the satellite into space have a limited weight limit. The second designing particular we incorporate is control. At last, we consolidate the building particular of volume.Accept that a different need list is produced for each dispatch since the spending levels for each dispatch are particular and there is no budgetary remainder between dispatches.

\subsection{Single-launch models with certainty}

The financial plan and building particulars (weight, control, volume, and so on.) oblige the quantity of unmistakable payloads that might be chosen for incorporation on a satellite transport. We accept that the financial spending plan for a solitary satellite dispatch is known with conviction, i.e., the measure of cash distributed for the satellite outline isn't helpless to change. Moreover, this structure is reasonable if the monetary allowance isn't known with assurance, yet the payload choice can be put off until the point that the financial backing ends up noticeably known, e.g., for the situation where the full task spending plan is granted simply after it is affirmed to be done. The single-dispatch issue with certain financial plan can be demonstrated as a multidimensional backpack issue (MDKP). The goal is to choose the arrangement of payloads to incorporate on a satellite transport keeping in mind the end goal to augment the reward, given a specific financial spending plan.

\subsection{Single-launch models with uncertainty}

For organizing payload dispatches which consider unverifiable spending designs, mission essentials and star grouping reliance. Without considering spending level, an enormously appealing payload will be picked under all spending circumstances. Finally, it is in like manner possible that a payload is picked at the more diminutive spending level yet not at a higher spending level. This can occur in light of the fact that at the lower spending level an all the more appealing payload (to the extent compensate) can't fit inside the budgetary arrangement, be that as it may it can fit at the more raised sum. Since it is uncommonly possible that the spending will change, and there is no affirmation that the decision will be dependable over all monetary arrangement circumstances, it is advantageous to create a composed once-over of payloads for thought on the satellite. The pioneer would then have the capacity to pick payloads from the summary until the point that the budgetary arrangement is drained.

In the event that the money related help is known as unending likelihood disseminating, we can utilize the extended PearsonTukey technique. This framework approximates an energetic course utilizing three discrete fixations by doling out the 0.05 fractile a likelihood of 0.185 , designating the inside likelihood of 0.63 , and transferring the 0.95 fractile likelihood of 0.185 . It has been demonstrated that the Pearson-Tukey performs well as a figure for a broad assortment of likelihood courses.

\subsection{Multiple-launch models}

Think about now as a grouping of dispatches which will populate or renew a satellite heavenly body in a limited time skyline. At settled time ages, a satellite will be propelled into space to help fulfil the group of stars' central goal necessities. Satellite mission organizers must consider the arrangement of the heavenly body with the goal that mission prerequisites are not ignored. Also, overlooking the piece of the group of stars can prompt huge cost invades because of unreasonable payload redundancies. While excess can expand the likelihood of meeting the mission necessity, propelling excessively numerous payloads is staggeringly costly.

\section{Conclusion}

This comparative study investigates diverse discipline of satellite communication, such as efficient data transfer between the satellite and the ground station, on-board data processing techniques, prioritizing the payload prioritization, load balancing and optimizing energy consumption issues in a detailed manner.It has been observed that manyresearch avenues are open up in satellite communication.

\section{References}

[1] Author, "Title of the Paper", Journal name, Vol.X, No.X, (200X), pp. XX-XX, available online: http://xxx, last visit: 28.02.2013.

[2] Author,"Title of the Paper", Proceedings of the conference name, Vol.X, No.X, (200X), pp:XX-YY, https://doi.org/10.1109/MMM.2013.2248651.

[3] Author, Title of the Book, Publisher, (200X), pp: XXX-YYY.

[4] Cho JH, Chang SA, Kwon HS, Choi YH, KoSH, Moon SD, Yoo SJ Song KH, Son HS, Kim HS, Lee WC, Cha BY, Son HY \& Yoon $\mathrm{KH}$ (2006), Long-term effect of the internet-based glucose monitor- 
ing system on HbA1c Reduction and glucose stability: a 30-month follow-up study for diabetes management with a ubiquitous medical care system. Diabetes Care 29, 2625-2631. https://doi.org/10.2337/dc05-2371.

[5] Fauci AS, Braunwald E, Kasper DL \& Hauser SL (2008), Principles of Harrison's Internal Medicine, Vol. 9, 17thedn. McGraw-Hill, New York, NY, pp.2275-2304.

[6] Kim HS \& Jeong HS (2007), A nurse short message service by cellular phone in type-2 diabetic patients for six months. Journal of Clinical Nursing 16, 1082-1087. https://doi.org/10.1111/j.13652702.2007.01698.x.

[7] Lee JR, Kim SA, Yoo JW \& Kang YK (2007), The present status of diabetes education and the role recognition as a diabetes educator of nurses in korea. Diabetes Research and Clinical Practice 77, 199204. https://doi.org/10.1016/j.diabres.2007.01.057.

[8] McMahon GT, Gomes HE, Hohne SH, Hu TM, Levine BA \& Conlin PR (2005), Web-based care management in patients with poorly controlled diabetes. Diabetes Care 28, 1624-1629. https://doi.org/10.2337/diacare.28.7.1624.

[9] Thakurdesai PA, Kole PL \& Pareek RP (2004), Evaluation of the quality and contents of diabetes mellitus patient education on Internet. Patient Education and Counseling 53, 309-313. https://doi.org/10.1016/j.pec.2003.04.001. 